\title{
Pemodelan Knowledge Dalam Proses Pemberian Beasiswa Bagi Mahasiswa Menggunakan Soft System Methodology (SSM) (Studi Kasus : Fakultas Keguruan dan Ilmu
Pendidikan Universitas Pattimura Ambon)
}

http://dx.doi.org/10.28932/jutisi.v5i1.921

\author{
Yulian Hany Makaruku ${ }^{* 1}$, Eko Sediyono ${ }^{\# 2}$, Irwan Sembiring \#3 \\ ${ }^{\#}$ Magister Sistem Informasi, Universitas Kristen Satya Wacana \\ Jl. Diponegoro 52-60 Salatiga, 5071-Indonesia \\ ${ }^{1}$ makaruku98@gmail.com \\ ${ }^{*}$ Magister Sistem Informasi, Universitas Kristen Satya Wacana \\ Jl. Diponegoro 52-60 Salatiga, 5071-Indonesia \\ ${ }^{2}$ eko@uksw. edu \\ *Magister Sistem Informasi, Universitas Kristen Satya Wacana \\ Jl. Diponegoro 52-60 Salatiga, 5071-Indonesia \\ 3 irwan@uksw. edu
}

\begin{abstract}
The process of scholarship awarding especially for the university students through the sub-section of student affairs is influenced by the students' background and achievements. The background of the students and the process of scholarship awarding in the sub-section of students affairs have the important role to support students' achievements and academic finance. The method that used in designing knowledge method to this scholarship awarding is the kualitative method with the soft system methodology approach and the steps that added in accordance with the case study. Knowledge management of FKIP Unpatti Ambon is ecpected to work well if there is an interaction between each component and there is no imbalance of the three components, they are knowledge management plot, appropriate technology, and conducive workplace habits. Knowledge management that is modeled using the SSM approach can provide opportunities to FKIP Unpatti Ambon in catching and analysing the information in the faculties. Faculties can implement it strategically in the form of warehousing, and decision support system. The establishment of a process for accessing information to all outside societies through the internet, groupware, and group decision support system is very needed, so that the stakeholders in the fakulties are informed properly, informatively and inovatively. This makes the motivation of knowkedge accumulated from organizational experience.
\end{abstract}

Keywords- Knowledge, Knowledge management, Soft System Methodology, CATWOE.

\section{PENDAhUluan}

Proses pemberian beasiswa khususnya untuk mahasiswa melalui sub bagian kemahasiswaan sangat dipengaruhi oleh latar belakang dan prestasi mahasiswa tersebut. Latar belakang mahasiswa dan proses pemberian beasiswa dalam sub bagaian kemahasiswaan mempunyai peranan penting untuk menunjang prestasi belajar mahasiswa dan keuangan akademik mahasiswa.

Sebagian mahasiswa dengan ekonomi yang tergolong rendah, dan kebanyakan mahasiswa yang mempunyai prestasi cukup baik, sehingga dari antara mahasiswa yang mempunyai ekonomi yang rendah ini bisa mendapatkan beasiswa Bidik Misi, untuk mendapatkan beasiswa ini mahasiswa diharapkan mempunyai akademik yang baik dengan IPK yang terpenuhi. Sedangkan untuk mahasisswa yang mempunyai tingkat ekonominya tergolong mampu dan mempunyai prestasi akademik yang baik mendapatkan beasiswa Peningkatan Prestasi Akademik (PPA). Akan tetapi informasi beasiswa bagi mahasiswa pada FKIP Unpatti ini mempunyai beberapa kendala, diantaranya informasi beasiswa yang di sampaikan dari pihak universitas melalui Fakultas kepada mahasiswa 
tidak sepenuhnya didengar oleh mahasiswa karena keterbatasan sarana informasi, dan masalah lainnya yaitu, dalam proses pemberian beasiswa ini memerlukan waktu yang cukup lama sehingga menghambat transformasi knowledge antara Kepala Bagian Mahasiswa, Staf Bagian Mahasiswa dan Fakultas.

Banyaknya mahasiswa yang mengajukan permohonan beasiswa ini menjadi hal penting dan perlu dikelola. Berbagai bentuk pemberian beasiswa ini dilakukan selalu melibatkan banyak orang. Dengan demikian banyak pengetahuan yang muncul dari kegiatan-kegiatan tersebut, baik itu pegawai, dosen, dan mahasiswa terlibat dalam proses pemberian beasiswa ini. Akan tetapi dalam pemberian beasiswa ini ada indikasi tentang pelanggaran yang dibuat seperti mahasiswa dengan tingkat ekonomi yang baik tetapi mendapatkan beasiswa Bidik Misi atau besiswa kurang mampu, dengan memasukan data yang tidak benar, dan juga mahasiswa yang tidak memenuhi persyaratan untuk mendapatkan beasiswa PPA, bisa mendapatkan beasiswa PPA, persyaratan yang di maksudkan ialah IPK harus di atas 3.00. Maka diperlukan model pengetahuan agar dapat melihat kecurangankecurangan yang terjadi dan pengetahuan yang sesuai tanpa ada kecurangan yang ada pada pemberian beasiswa.

Pengetahuan-pengetahuan yang terbentuk dalam proses pemberian beasiswa ini dilakukan secara maksimal oleh pihak fakultas agar dalam pemberian beasiswa ini dapat berjalan sesuai yang diharapkan dan terhindar dari pada segala bentuk pelanggaran manipulasi data-data mahasiswa dan kecurangan-kecurangan yang dilakukan.

Soft System Methodology (SSM) dipilih sebagai pendekatan untuk memberikan gambaran secara menyeluruh tentang situasi di Fakultas Keguruan dan Ilmu Pendidikan khususnya pada Sub Bagian Kemahasiswan sehingga proses transfer pengetahuan dapat dilakukan dengan maksimal. Penelitian yang dilakukan sebelumnya bahwa SSM cocok diterapkan untuk memodelkan pengolahan pengetahuan dalam organisasi. Karena itu penelitian ini ditujukan untuk menghasilkan sebuah model yang dapat digunakan untuk mentransfer pengetahuan dengan memanfaatkan SSM sebagai metode penyelesaiannya.

\section{PENELITIAN TERKAIT}

Penelitian sebelumnya yang berjudul Knowledge Management Model and Strategy of Genetic and Traditional Knowledge in Indonesia Membahas model Knowledge dan strategi yang cocok menerapkan pengelolaan sumber daya genetic dan pengetahuan tradisional di Indonesia. Tujuan penelitiannya adalah menyediakan ketersediaan model pengelolaan pengetahuan dan strategi genetic sumber daya dan pengetahuan tradisional yang dimiliki oleh Indonesia. Penelitian ini menerapkan Soft System Methodology dengan menggunakan data dan informasi dari lembaga penelitian [1].

Penelitian terkait lainnya yaitu jurnal yang berjudul Development Customer Management (CKM) Models in Purbalingga Hospitalilty Using Soft System Methodology (SSM). Penelitian ini dilakukan dengan membuat gambaran model Customer Knowledge Management untuk mengatasi permasalahan yang ada pada perhotelan di Purbalingga untuk mendukung pariwisata, sehingga dapat ikut berkontribusi pada perkembangan pariwisata di Indonesia. Penelitian ini merupakan research action dengan metode Soft System Methodology (SSM) untuk menemukan cara terbaik dalam menghadapi situasi yang harus dihadapi dalam kehidupan sehari-hari, khususnya dalam menghadapi permasalahan pada perhotelan di Purbalingga. Validasi yang dilakukan untuk penelitian ini antara lain menggunakan pendekatan secara teoritis, expert judgement dan user pada objek penelitian. Dari penelitian yang dilakukan, dihasilkan sebuah model Customer Knowledge Management pada perhotelan di Purbalingga dan rekomendasi yang disesuaikan dengan permasalahan dan kebutuhan pada perhotelan di Purbalingga[2].

Penelitian berikutnya yang berjudul Strategi Management Untuk Meningkatkan pengetahuan Berdasarkan Knowledge-Based Oerganization Model. Fokus dari penelitian ini untuk pencarian solusi dalam penerapan strategi knowledge management supaya menyelesaiakan permasalahan yang dihadapi karyawan. Sebelum melakukan implementasi knowledge based organizational model maka diperlukan pengukuran terlebih dahulu berkaitan dengan mutu maupun kualitas sumber daya manusia yang ada pada PT Telekomunikasi Indonesia mengguanakan skala linkert dan pengujian mutu management sumber daya manusia dengan penggabungan pendekatan knowledge management serta iso 9000 dan EFQM (European Foundation for Quality Management)[3].

Penelitian lainnya yang berjudul Evaluasi Pemanfaatan Media Sosial sebagai Sarana Knolwedge Sharing. Tujuan dari penelitian ini yaitu mengevaluasi pemanfaatan aplikasi sosial media yang digunakan sebagai sarana berbagi penegetahuan oleh dosen di Indonesia dalam sebuah group virtual di Facebook. Model kesuksesan sistem indormasi oleh Delone dan MCLean digunakan sebagai teori dasar dengan mempertimbangkan faktor karasteristik Individu [4].

\section{TINJAUAN PUSTAKA}

\section{A. Definisi Knowledge}

Knowledge (pengetahuan) adalah informasi yang kontekstual, relevan dan "actionable" [5], alat pragmatis untuk memanipulasi dan mengontrol dunia [6], bersifat komunal,aktivitas spesifik, terdistribusi dan historiscultural[7]. 
Umumnya, para pakar membagi knowledge ke dalam 1 jenis [5], yaitu : (1) Tacit Knowledge, yaitu pengetahuan yang bersifat subyektif, kognitif dan pembelajaran yang berasal dari pengalaman[8], sebagai pengetahuan yang tertanam (embedded knowledge) yang relatif sulit untuk dikeluarkan dari sumbernya (sticky knowledge).

Dalam konteks organisasi, tacit knowledge merupakan penyimpanan kumulatif dari pengalaman, peta mental, wawasan, ketajaman, keahlian, knowhow, rahasia dagang, kumpulan kecakapan dan pembelajaran yang dimiliki organisasi, termasuk pula budaya organisasi yang telah tertanam dalam pengalaman masa lalu dan saat ini dari SDM, proses dan nilai. (1) Explicit Knowledge, yaitu pengetahuan yang bersifat objektif, rasional dan teknis. Disebut juga sebagai leaky knowledge karena sifatnya yang mudah untuk ditinggalkan dari seseorang, dokumen atau organisasi setelah semuanya didokumentasikan. Dalam konteks organisasi, explicit knowledge merupakan kebijakan, prosedur tetap, laporan, white paper, rancangan, strategi, tujuan, misi dan kompetensi inti dari organisasi dan infrastruktur teknologi informasi. Selain itu ada yang menambahkan satu jenis lagi knowledge, yaitu pengetahuan kultural (cultural knowledge), yang merupakan model untuk memahami dunia yang diekspresikan dalam asumsi-asumsi, nilai-nilai dan normanorma yang dimiliki manusia[9].

\section{B. Soft System Methodology (SSM)}

Soft System Methodology (SSM) adalah proses penelitian sistemik yang menggunakan model-model sistem [10]. Pengembangan model sistem tersebut dilakukan dengan melakukan penggalian permasalahan yang tidak terstruktur, mendiskusikan secara intensif dengan pihak terkait, membandingkan konsep system thinkin dengan real word, dan melakukan penyelesaian masalah secara bersama.

Soft System Methodology Mempunyai tujuan tahapan yaitu,[10]

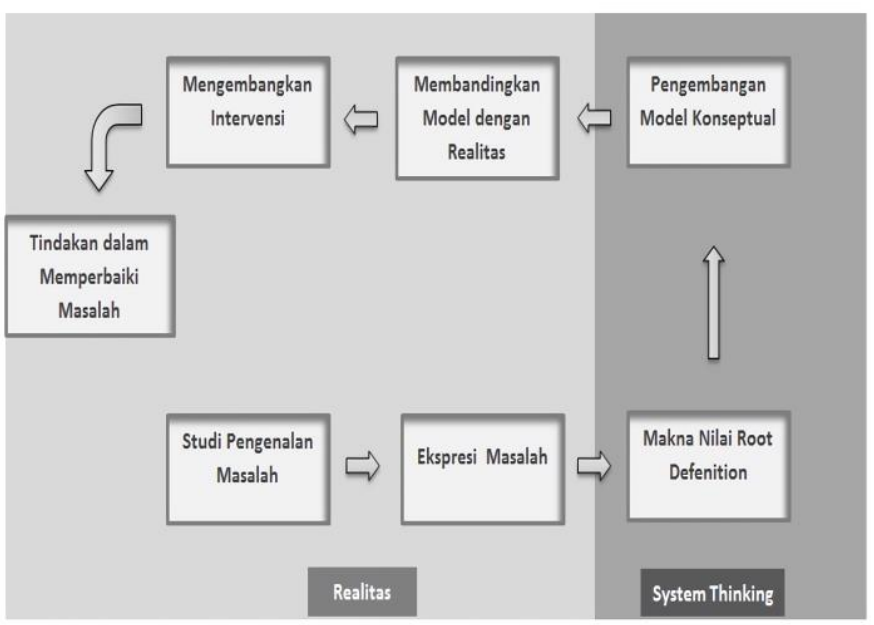

Gambar 1. Tahapan Soft System Methodology[10]
Penjelasan Gambar 1 dipaparkan dibawah ini.

a. Studi Pengenalan Masalah

Pada bagian ini, dibuat identifikasi dan deskripsi singkat tantang situasi yang ada dalam organisasi.

b. Ekspresi Masalah (Rich-Picture)

Tahap kedua, mengumpulkan data dan informasi yang selanjutnya dituangkan dalam bentuk rich picture.

c. Makna Nilai Root Definition

Tahap ketiga yaitu membuat Root Definition (RD) yaitu menjelaskan proses (transformasi) untuk mencapai tujuan. RD biasanya dimulai dengan kalimat "Sistem Untuk...'. Analisis Terhadap RD dilakukan dengan menggunakan identifikasi CATWOE, dapat dilihat pada Tabel I.

TABEL I

IDENTIFKASI CATWOE

\begin{tabular}{|c|c|}
\hline CATWOE & Definisi \\
\hline Customer & $\begin{array}{l}\text { Pihak-pihak yang } \\
\text { mendapatkan manfaat atau } \\
\text { keuntungan dari transformasi } \\
\text { ini }\end{array}$ \\
\hline Actor & $\begin{array}{l}\text { Pihak yang memfasilitasi } \\
\text { transformasi ini kepada } \\
\text { customers. }\end{array}$ \\
\hline Transformastion & $\begin{array}{l}\text { Perubahan yang akan dicapai, } \\
\text { biasanya mendifinisikan } \\
\text { kondisi awal dan kondisi akhir } \\
\text { yang akan dicapai. }\end{array}$ \\
\hline Waltanschauug(Worldview) & $\begin{array}{l}\text { Pandangan umum yang } \\
\text { memberikan statement } \\
\text { mengapa transformasi tersebut } \\
\text { perlu dilakukan. }\end{array}$ \\
\hline Owners & $\begin{array}{l}\text { Pihak yang mendapat } \\
\text { menghentikan transformasi } \\
\text { tersebut. }\end{array}$ \\
\hline Environment constraints & $\begin{array}{l}\text { Faktor yang mempengaruhi } \\
\text { transformasi tetapi tidak } \\
\text { mengendalikan sistem. }\end{array}$ \\
\hline
\end{tabular}

d. Pengembangan Model Konseptual

Pada tahap keempat, dibangun model konseptual berdasarkan tahap ketiga. Model konseptual adalah representasi grafis dari perspektif pada RD. Langkah pertama dalam menggambarkan model adalah mengidentifikasi semua kata kerja dalam $\mathrm{RD}$, kata kerja yang dapat mewakili beberapa bentuk kegiatan. Untuk setiap kata kerja ada setidaknya satu kata benda atau kata ganti yang terkait (subjek atau objek kosakata) yang menunjukan siapa yang melakukan suatu kegiatan atau yang penerima kegiatan. Perlu juga diperhatikan rincian dari setiap kegiatan yang diidentifikasi untuk memastikan baaimana, kapan dan apa saja yang dilakukan.

e. Membandingkan Model dengan Realitas 
Tahap kelima yang dilakukan adalah membandingkan model konseptual dengan situasi yang digambarkan pada tahap kedua.

f. Mengembangkan Intervensi

Tahap keenam yaitu dilakukan perubahan yang diinginkan.

g. Tindakan Dalam Memperbaiki Masalah Mengambil tindakan untuk memperniki masalah.

\section{Knowledge Goal}

Knowledge goal memberikan arahan pada knowledge management dan menentukan kemampuan yang harus ada dan berada pada level yang mana. Terdapat tiga macam knowledge goal yaitu normatif, strategic dan operational. Normatif knowlwdge lebih kearah pembangunan budaya yang berbasis knowledge di dalam perusahaan yang akan mendukung tercapainya strategic dan operational goal. Operatioan knowledge lebih ke arah pencapaian terget operasional (jangka pendek) yang berpengaruh kepada posisi perusahaan di pasar. Strategic knowledge goal lebih ke arah merumuskan sasaran dan perbaikan serta target (jangka panjang) organisasi[11].

\section{Knowledge Management}

Knowledge Management (KM) adalah suatu rangkaian kegiatan yang digunakan oleh organisasi atau perusahaan untuk mengidentifikasi, menciptakan, menjelaskan, dan mendistribusikan pengetahuan untuk digunakan kembali, diketahui, dan dipelajari di dalam organisasi[12].

\section{METODE PENELITIAN}

Metode yang digunakan dalam membuat model knowledge untuk pemberian beasiswa ini dengan pendekatan Soft System Methodology dengan langkahlangkah yang ditambahkan sesuai dengan studi kasus. Ada tiga Teknik pengumpulan data dalam penelitian ini yaitu wawancara, observasi, dan dokumentasi.

Pemodelan knowledge proses pemberian beasiswa pada Fakultas Keguruan dan Ilmu Pendidikan Unpati Ambon mengacu pada metode Soft System Methodology dengan langkah-langkah sebagai berikut.

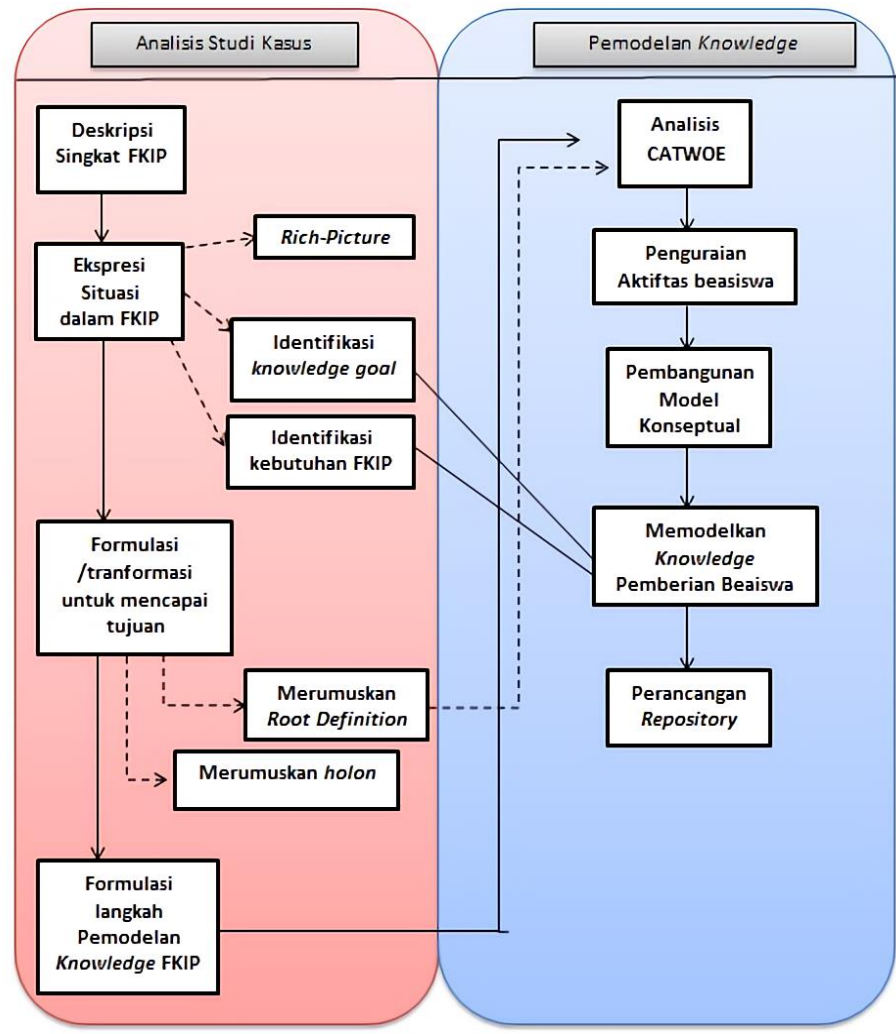

Gambar 2. Kerangka Penyelesaian Masalah

Tahapan penyelesaian masalah yang digambarkan pada gambar 2 dalam penelitian ini dikelompokan menjadi dua bagian besar yaitu proses analisis studi kasus dan pemodelan knowledge yang akan menjadi tujuan dari model penelitian ini. Dalam kerangkan kerja pada gambar 2 ini beberapa proses di tandai dengan kotak yang bergaris tebal, dengan maksud bahwa proses tersebut mengacu dari langkah Soft System Methodology. Kerangka penyelesaian masalah pada gambar 2 dengan analisis studi kasus akan dijabarkan tentang deskripsi situasi proses pemberian beasiswa pada Fakultas Keguruan dan Ilmu Pendidikan, mengekspresikan situasi proses pemberian beasiswa FKIP dalam rich-picture, mengidentifikasi knowledge goal, mengidentifikasi kebutuhan knowledge proses pemberian beasiswa, kemudian melakukan formulasi proses pencapaian tujuan melalui root definition, holons, dan framework KM pemberian beasiswa, setelah itu melakukan langkah-langkah pemodelan knowledge pemberian beasiswa.

\section{HASIL DAN PEMBAHASAN}

Analisis dilakukan untuk memberikan gambaran kerangka tepat dalam membangun model konseptual. Model konseptual terdiri dari faktor-faktor yang dibutuhkan untuk memenuhi tujuan (RD). Selanjutnya dibuat model penerapan yang disarankan untuk mencapai knowledge goal berdasarkan model konseptual yang 
temukan, setelah itu dibandingkan dengan holon guna pencapaian pengelolaan knowledge pada FKIP.

\section{A. Deskripsi Singkat dan Ekspresi Situasi Fakultas}

Proses yang pertama, dilakukan penelitian di FKIP dengan metode penilitian wawancara dengan staf dan Pembantu Dekan III yang terlibat menangani proses pemberian beasiswa dan diperoleh informasi antara lain tentang tujuan stakeholder dan peranannya.

Proses kedua yaitu, deskripsi singkat situasi dalam bentuk Rich-Picture, dengan menggambarkan semua aktor yang ada pada keadaan sekarang kemudian diuraikan beberapa pengetahuan yang dimiliki serta kebutuhan knowledge setiap aktor yang belum terpenuhi. Richpicture dapat dilihat pada gambar 3 dan penjelasannya pada tabel II.

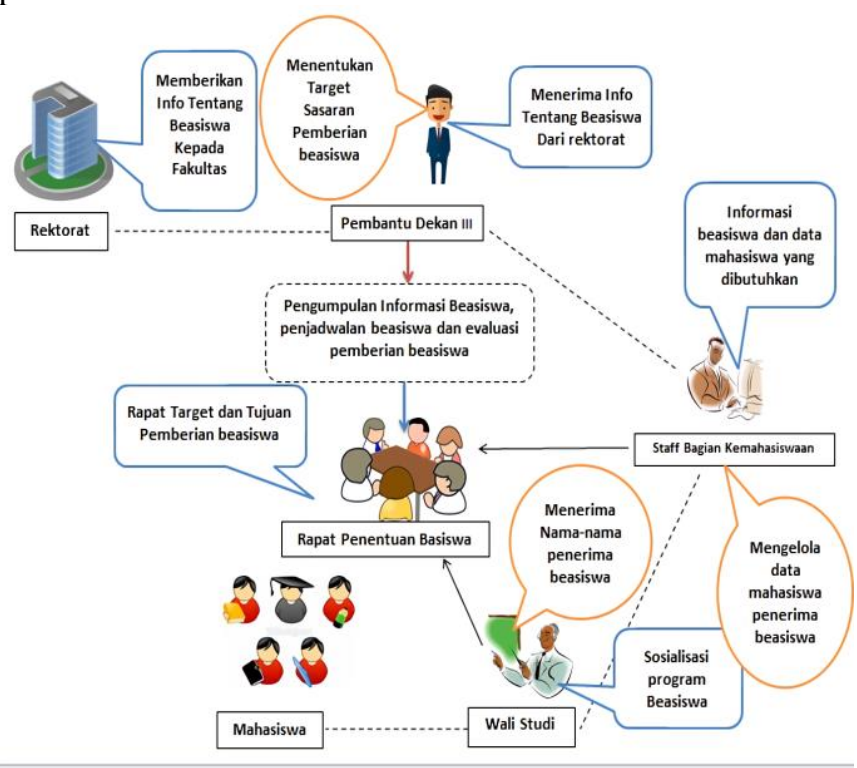

Gambar 3 Rich-Picture Fakultas Keguruan dan Ilmu pendidikan Universitas Pattimura Ambon

TABEL II

RICH-PICTURE FAKULTAS KERUAN DAN ILMU PENDIDIKAN

\begin{tabular}{ll}
\hline Simbol & \multicolumn{1}{c}{ Keterangan } \\
\hline & $\begin{array}{l}\text { Arah kemana informasi } \\
\text { disampaikan }\end{array}$ \\
\hline & $\begin{array}{l}\text { Unsur yang menyampaikan } \\
\text { Inoformasi beasiswa } \\
\text { Keadaan yang } \\
\text { menggambarkan kebutuhan } \\
\text { pelaku yang belum } \\
\text { terpenuhi }\end{array}$ \\
\hline $\begin{array}{l}\text { Garis yang menyatakan } \\
\text { elemen saling berhubungan } \\
\text { Keadaan yang diketahui } \\
\text { oleh pelaku }\end{array}$ \\
\hline
\end{tabular}

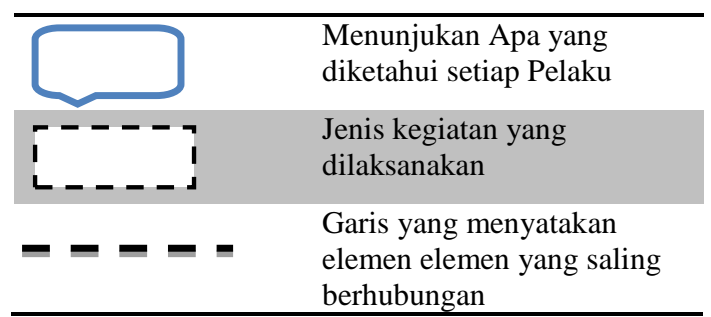

Gambar 2 menjelaskan situasi yang ada pada Fakultas Keguruan dan Ilmu Pendidikan Universitas Pattimura dalam bentuk Rich-picture, dapat dijelaskan tentang keadaan dan pelaku-pelaku yang secara langsung terlibat dengan kegiatan pemberian beasiswa pada Fakultas Keguruan dan Ilmu Pendidikan Universitas Pattimura. Pelaku-pelaku ini mencakup, rektorat, pembantu dekan III, staf bagian kemahasiswaan, wali studi, mahasiswa. Richpicture menampilkan tentang keterkaitan antara masingmasing pelaku di Fakultas Keguruan dan Ilmu Pendidikan Universitas Pattimura. Selain itu juga digambarkan proses kegiatan dan penanganan pemberian informasi dan pemberian beasiswa berlangsung.

\section{B. Analisis CATWOE}

Analisis CATWOE untuk tiap holon di tuangkan dalam Tabel III. Dijelaskan analisis dari 2 holon yang diperoleh dari rich-picture pada penjelasan sebelumnya. Masing-masing holon dijelaskan berdasarkan customer, actors, transformation, Waltanschauug dan environment.

TABEL III

ANALISIS CATWOE

\begin{tabular}{|c|c|c|}
\hline \multirow{2}{*}{\multicolumn{2}{|c|}{$\frac{\text { CATWOE }}{\text { Holon } 1}$}} & Definisi \\
\hline & & $\begin{array}{l}\text { Kepala Bagian dan staf yang } \\
\text { bertanggung jawab dalam proses } \\
\text { pemberian informasi beasiswa dan } \\
\text { proses pembagian beasiswa, dapat } \\
\text { mengetahui keadaan dan kondisi } \\
\text { proses dan alur pembagian } \\
\text { beasiswa bagi mahasiswa. }\end{array}$ \\
\hline 1 & Customer & $\begin{array}{l}\text { Rektorat } \\
\text { KKIP, Pembantu Dekan 3, } \\
\text { Kabag Kemahasiswaan, } \\
\text { Bagian Kemahasiswaan, Ketua } \\
\text { Program Studi }\end{array}$ \\
\hline & Actor & $\begin{array}{l}\text { Rektorat } \\
\text { KKIP, Pembantu Dekan 3, } \\
\text { Kabag Kemahasiswaan, } \\
\text { Bagian Kemahasiswaan, Ketua } \\
\text { Program Studi. }\end{array}$ \\
\hline & $\begin{array}{l}\text { Transforms } \\
\text { tion }\end{array}$ & $\begin{array}{l}\text { Customer dapat berbagi knowledge } \\
\text { dengan Customer dalam proses } \\
\text { implementasi pemberian beasiswa. }\end{array}$ \\
\hline & $\begin{array}{l}\text { Waltanscha } \\
\text { uug(Worldv } \\
\text { iew) }\end{array}$ & $\begin{array}{l}\text { Dapat mengurangi kekurangan } \\
\text { dalam proses informasi beasiawa } \\
\text { dan proses pemberian beasiswa. }\end{array}$ \\
\hline & Owners & $\begin{array}{l}\text { Fakultas Keguruan dan Ilmu } \\
\text { Pendidikan Universitas Pattimura } \\
\text { Ambon. }\end{array}$ \\
\hline
\end{tabular}




\begin{tabular}{|c|c|c|}
\hline & $\begin{array}{l}\text { Environme } \\
\text { nt } \\
\text { constraints }\end{array}$ & $\begin{array}{l}\text { Ada beberapa kendala } \\
\text { mentransfer knowledge } \\
\text { pemberian beasiswa. }\end{array}$ \\
\hline & Holon 2 & $\begin{array}{l}\text { Pengalaman dari bagian } \\
\text { kemahasiswaan maupun staf dapat } \\
\text { dijadikan sebagai pengetahuan } \\
\text { untuk melakukan perbaikan. }\end{array}$ \\
\hline 2 & Cust & $\begin{array}{l}\text { Rektorat } \text { FKIP, Pembantu Dekan 3, } \\
\text { Kabag Kemahasiswaan, raf } \\
\text { Bagian Kemahasiswaan, Ketua } \\
\text { Program Studi. }\end{array}$ \\
\hline & Actor & 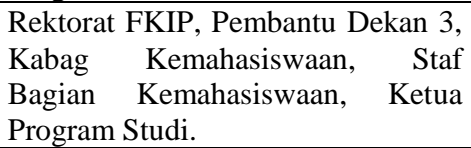 \\
\hline & $\begin{array}{l}\text { Transforma } \\
\text { tion }\end{array}$ & $\begin{array}{l}\text { Sistem yang dapat merekam } \\
\text { keterangan tentang keadaan } \\
\text { informasi beasiswa dan target } \\
\text { pemberian beasiswa pada saat } \\
\text { informasi beasiswa dikeluarkan. }\end{array}$ \\
\hline & $\begin{array}{l}\text { Waltanscha } \\
\text { uug(Worldv } \\
\text { iew) }\end{array}$ & $\begin{array}{l}\text { Bagian kemahasiswaan tidak harus } \\
\text { membuang atau menyimpan } \\
\text { pengetahuan melainkan di sharing. }\end{array}$ \\
\hline & Owners & $\begin{array}{l}\text { Fakultas } \text { Keguruan dan Ilmu } \\
\text { Pendidikan } \text { Universitas Pattimura } \\
\text { Ambon. }\end{array}$ \\
\hline & $\begin{array}{l}\text { Environme } \\
\text { nt } \\
\text { constraints }\end{array}$ & $\begin{array}{l}\text { Tidak ada sarana untuk merekam } \\
\text { dan membagi pengalaman atau } \\
\text { pengetahuan yang sudah di dapat. }\end{array}$ \\
\hline
\end{tabular}

\section{Model Konseptual Knowledge Management FKIP Pattimura Ambon}

Perlu dibuatnya model knowledge management pada FKIP Pattimura Ambon yang merupakan seleksi dan pengelola knowledge, nantinya akan digunakan untuk mengidentifikasi, memahami dan menguasai knowledge pada bagian tertentu. Agar supaya dapat mendorong terjadinya dan dihargainya suatu knowledge sharing, contohnya pada bagian yang ada pada FKIP Unpatti Ambon melalui kontak pribadi ataupun kelompok, yang didapat dari tacit knowledge para staf atau Kepala Bagian yang berasal dari knowledge masing-masing orang atau kelompok tentang pengalaman mereka. Penguasaan pada knowledge tersebut dipahami dan dikuasai oleh organisasi, maka knowledge akan menjadi suatu hal yang penting bagi organisasi pada FKIP Unpatti Ambon.

Aktifitas pada FKIP Unpatti Ambon dapat dijabarkan, dan diperoleh unsur yang bisa dibentuk knowledge management pada gambar 4 .

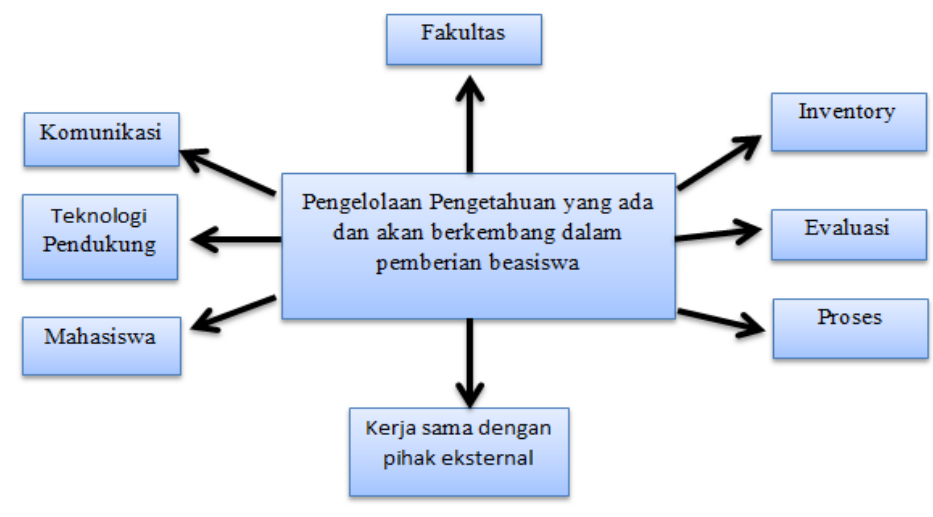

Gambar 4. Model Konseptual desain arsitektur Pemodelan Knowledge Pemberian Beasiswa FKIP Unpatti

Gambar 4 adalah model konseptual yang dibangun di atas rincian kegiatan Pemberian Beasiswa bagi mahasiswa, yang kemudian dibuat root definisi yang akan dicapai. Untuk mencapai ini semua faktor-faktor diuraikan dalam kata benda untuk mendukung pencapain yang perspektif. Dalam SSM, model konseptual biasanya menggambarkan faktor dalam bentuk kata kerja atau aktivitas untuk setiap jenis pekerjaan dalam bentuk hal-hal yang perlu dicapai pada definisi root. Dalam penelitian ini model konseptual dibentuk dalam kata benda, dikarenakan setiap staf atau aktor dapat mengelola lebih dari satu faktor, dan setiap faktor dapat dikelola lebih dari satu staf atau aktor. Oleh karena itu, model konseptual dibuat dalam bentuk kata benda dengan kegiatan yang berasal dari deskripsi situasi yang ada pada proses pemberian beasiswa pada FKIP.

D. Model Knowledge Management FKIP Universitas Pattimura Ambon

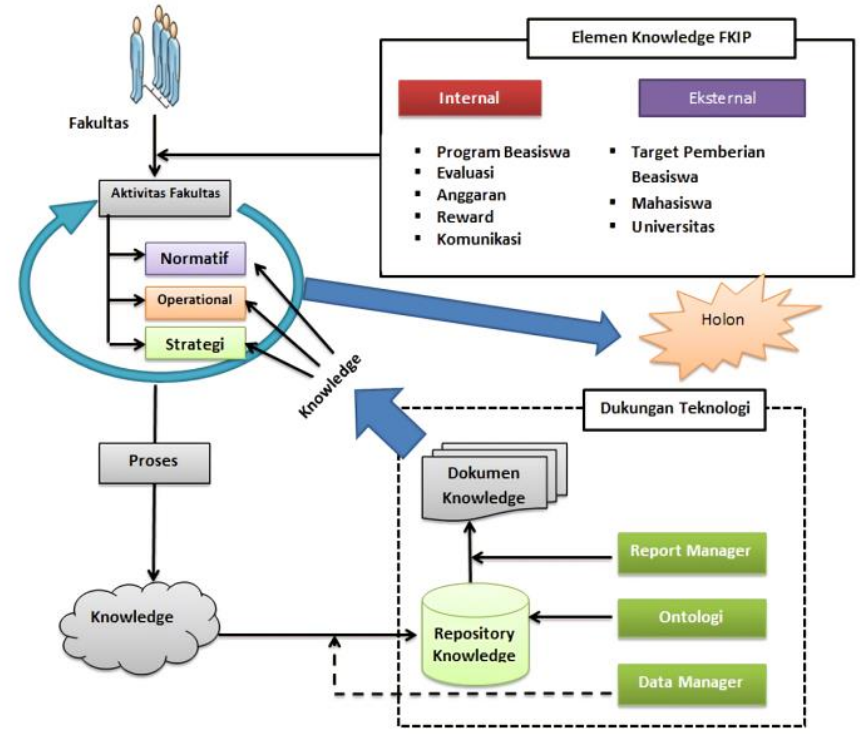

Gambar 5. Model Knowledge pemberian beasiswa FKIP Universitas Pattimura Ambon 
Dapat dijelaskan pada gambar 5 dalam menjalankan proses pemberian beasiswa terdapat beberapa elemenelemen yang termasuk dalam FKIP khususnya bagian kemahasiswaan. Elemen-elemen yang terlibat di dalam FKIP ini dibagi manjadi tiga kategori yaitu normatif, operational, dan strategi. Tujuan dari pengkategorian ini disesuaikan dengan konsep knowledge goals menurut Probs. Dengan demikian dapa dipastikan secara setara antara sumber knowledge dengan hasil knowledge. Proses pemberian beasiswa menghasilkan prespektif yang diharapakan (disebut sebagai holon yang diacu dari SSM) yang berkaitan dengan kebutuhan knowledge.

Selain adanya holon, proses pemberian beasiswa juga menghasilkan knowledge yang masih dalam bentuk yang belum terstruktur. Oleh karena itu, dibutuhkan teknologi berupa data manager dan report manager sebegai alat yang menjembatani proses perekaman knowledge ke dalam repository dan proses-proses penyeleksian terhadap dokumen knowledge yang berasal dari knowledge yang sudah terekam di dalam repository knowledge. Data manager dan report manager di buat dalam bentuk software dan di sesuaikan dengan knowledge yang berkembang. Pada model knowledge proses pemberian beasiswa data manager dan report manager merupakan sebuah fungsi yang bisa saja terjadi perubahan dalam bentuk perangkat input dan laporan yang disesuaikan dengan perkembangan knowledge yang terjadi.

Repository knowledge menjadi aspek penting untuk mendukung tersimpannya knowledge yang di miliki oleh FKIP khusunsya bagian kemahasiswaan dalam bentuk yang terstruktur.

Dokumen knowledge sebagai hasil dari knowledge pemberian beasiswa dapat membantu FKIP khususnya bidang kemahasiswaan dalam menjalankan aktifitasnya. Di dalam knowledge goal diatur bahwa pencapaian terhadapa pengelolaan knowledge dilakukan dalam 3 macam goals, yaitu normatif, operational, dan strategic. Dokumen knowledge dapat membantu aktifitas bidang kemahasiswaan yang telah disesuaikan dengan konsep knowledge goals.

\section{E. Aktifitas FKIP Universitas Pattimura Ambon}

Aktifitas FKIP dikategorikan menjadi tiga kategori antara lain normatif, operational dan strategic berdasarkan dengan konsep knowledge goals.

Aktifitas normatif dalam FKIP merupakan aktifitas yang berkaitan dengan perilaku sehari-hari atau kebiasaan yang sering terjadi dalam Fakultas selama melaksanakan kegiatan dalam proses pemberian beasiswa. Aktifitas operational dalam Fakultas yaitu aktifitas yang bersifat praktis dan berkaitan dengan operational dalam Fakultas. Penjabaran aktifitas operational dalam Fakultas dijabarkan dari aktifitas peluang knowledge. Aktifitas strategic adalah aktifitas yang didalamnya berkaitan dengan rencana-rencana jangka panjang atau proses penetuan sasaran pemberian beasiswa bagi mahasiswa yang akan disesuaikan dengan sumber daya yang ada. Aktifitas ini dalam fakultas juga dijabarkan dari aktifitas peluang sumber knowledge.

\section{F. Data Manager}

Data manager adalah fungsi yang disediakan dalam bentuk software untuk menangkap knowledge yang masih dalam bentuk tidak terstruktur. Dibutuhkan proses untuk dapat manjadikan knowledge ini terstruktur menjadi bentuk data-data. Proses untuk menangkap knowledge yang muncul dari aktifitas proses pemberian beasiswa akan di pilah-pilah berdasarkan elemen-elemen FKIP, dan di analisis properti penyimpanan data yang perlu di dalam repository knowledge, dan pemanfaatan knowledge (expicit dan tacit) yang dapat diperoleh, dari olahan data tersebut. Proses yang dikerjakan meliputi elemen program beasiswa, evaluasi, komunikasi, anggaran, reward, fakultas, mahasiswa, target beasiswa. Kemudian propertiproperti yang diperoleh distrukturkan ke dalam konsep dan properti untuk repository knowledge.

\section{G. Repository Knowledge}

Repository knowledge berguna untuk menyimpan data yang berasal dari hasil penstrukturan knowledge. Rancangan repository knowledge menggambarkan dua komponen yang mendasar dari knowledge yaitu sebagai sebuah objek yang terdiri dari struktur dan konsep. Knowledge yang bersifat tidak terstrukur melainkan menpunyai keterkaitan antara pengetahuan satu dengan yang lain. Penyimpanan dengan menggunakan fasilitas database management manjadi kaku dan memerlukan operasi untuk menggabungkan tabel yang kompleks. Maka diperlukan mekanisme yang dapat digunakan untuk mengelola data (fungsinya untuk membentuk knowledge) sehingga pengetahuan dapat ditelusuri dan diakses dengan cepat.

\section{H. Report manager}

Report manager bertujuan untuk menghasilkan dokumen knowledge sesuai dengan kebutuhan apa yang dibutuhakan pengguna knowledge sehingga banyak dokumen yang dihasilkan. Dalam pemanfaatannya tidak digunakan, perlu adanya pertimbangan sesuaidengan apa yg dibutuhkan. Pengolahan ini berfungsi untuk menyeleksi data yang akan diolah untuk menghasilkan dokumen knowledge.

\section{Knowledge Goals}

Dokumen knowledge yang terbentuk dari proses sebelumnnya dapat dimanfaatkan fakultas untuk mendukung pencapaian knowledge dalam tiga level yaitu, normatif, operational, dan strategic. Pencapaian dari tiap knowledge saling mendukung satu sama lain akan di jelaskan sebagai berikut.

Pencapaian terhadapa normatif knowledge goals terjadi apabila pegawai staf kemahasiswaan terbiasa untuk 
menerapkan perilaku berbagi pengetahuan di dalam aktifitas fakultas.

Pencapaian terhadap operational knowledge goal terjadi sat prosedur berbagi knowledge melalui pendataan di dalam database dapat diikuti oleh staf dan pegawai kamahasiswaan fakultas dalam menjalankan proses pemberian beasiswa.

Secara keseluruhan dengan adanya knowledge yang terekam secara terstruktur dan secara historis disimpan maka dapat digunakan untuk keputusan-keputusan yang strategic. Misalnya dengan melihat pola yang terjadi pada proses pemberian beasiswa sebelumnya, dengan melihat inventaris pemberian beasiswa yang pernah dipakai untuk nantinya dipakai sebagai proses pemberian beasiswa berikutnya.

\section{J. Analisis Model KM Fakultas Untuk Menjawab Holon Dalam CATWOE}

Holon merupakan penjabaran dari RD yang di bentuk berdasarkan kondisi nyata yang dibuat, model KM yang sudah dibangun mampu menjawab holon dengan penjabaran berdasarkan tip holon sebagai berikut.

Holon 1 : Kepala Bagian dan staf yang bertanggung jawab dalam proses pemberian informasi beasiswa dan pembagian beasiswa, dapat mengetahui keadaan dan kondisi proses dan alur pembagian beasiswa bagi mahasiswa. Holon 1 dapat terjawab saat para pelaksana pembagian beasiswa mengakses dokumen knowledge dalam bentuk laporan yang dihasilkan dari database perekaman KM, tentang apa saja yang harus dipersiapkan dalam proses pemberian beasiswa untuk melihat sasaran dan proses berjalannya pemberian beasiswa yang dilakukan sebelumnya.

Holon 2 : Pengalaman dari bagian kemahasiswaan maupun staf dapat dijadikan sebagai pengetahuan untuk melakukan perbaikan. Holon 2 dapat terjawab saat para pelaksana menyimpan pengetahuan yang dimiliki mengikuti dalam database kontent. Usulan para pelaksana pemberian beasiswa dapat disimpan di dalam database dalam bentuk dokumen knowledge yang berisi laporan diskusi dalam forum, yang memuat usulan baru, orang yang memberi usulan, serta tanggapan dari staf fakultas atas usulan tersebut.

\section{K. Tanggapan Model Knowledge Management FKIP Universitas Pattimura Ambon}

Setelah model knowledge management di buat ada beberapa tanggapan yang di berikan dari pihak fakultas setelah melakukan wawancara dengan pihak fakultas tentang model knowledge yang dibuat, tanggapan dari pihak fakultas sebagai berikut : Menurut Prof. Dr. Theresia Laurens, M.Pd model knowledge yang dibangun mungkin dapat diterapakan di FKIP Unpatti dalam membantu proses sharing knowledge dan membantu bagian staf kemahasiswaan untuk proses pembagian beasiswa. Menurut Dr. Hasan Tuaputty model knowledge diharapkan dapat diterapkan pada FKIP Unpatti agar dapat membantu berjalannya proses pemberian beasiswa, karena selama ini dalam proses pemberian beasiswa dan sharingsharing knowledge antar staf yang ada dalam bidang kemahasiswaan dan dosen yang ikut terlibat masih sangat minim.

\section{SIMPULAN}

Pemodelan Knowledge Management pemberian beasiswa pada Fakultas Keguruan dan Ilmu Pendidikan Universitas Patimura Ambon telah berhasil dibangun dengan menggunakan pendekatan Soft System Methodology dengan langkah-langkah yang telah disesuaikan dengan studi kasus. Pemodelan knowledge yang dihasilkan memuat elemen-elemen yang dianggap memberikan knowledge dalam pemberian beasiswa pada FKIP Unpatti serta proses-proses yang perlu dilakukan dalam rangka mewujudkan Knowledge pada proses pemberian beasiswa. Proses pengelolaan knowledge untuk tiap elemen diatur berdasarkan knowledge goal. Hal tersebut dikarenakan pencapaian terhadap setiap knowledge goal, merupakan pencapaian terhadap Root Definition.

Model knowledge yang dihasilakn menerapkan pendekatan knowledge management melalui penggabungan antara knowledge yang tersembunyi dalam elemen-elemen yang diapaparkan dalam model, prosesproses yang dibuat untuk tiap elemen, dengan perancangan sistem berbasis teknologi. Model ini menghasilkan proses-proses untuk menangkap knowledge, menghasilkan dokumen-dokumen knowledge yang dapat dimanfaatkan oleh bagian kemahasiswa Fakultas Keguruan dan Ilmu Pendidikan Universitas Patimura Ambon.

Knowledge management pada FKIP Unpatti Ambon ini diharapkan akan berjalan sukses apabila terjadi interaksi diantara setiap komponennya dan tidak terjadi ketimpangan dari ketiga komponen tersebut yaitu, alur knowledge managementnya, teknologi yang sesuai dan kebiasaan tempat kerja yang kondusif. Knowledge management yang dimodelkan dengan menggunakan pendekatan SSM tersebut, sehingga memberikan kesempatan bagi FKIP Unpatti Ambon untuk menangkap dan menganalisa informasi yang dimiliki di fakultas. Fakultas dapat melakukan implementasiya secara strategis dalam bentuk warehousing, datamining, dan sistem pendukung keputusan. Perlunya menciptakan proses untuk akses informasi keseluruh masyarakat luar dapat melalui internet, groupware, dan sistem pendukung keputusan kelompok agar stakeholder di fakultas mendapat informasi secara tepat, informative dan inovatif. Hal ini menjadikan motivasi dari knowledge yang terakumulasi dari pengalaman organisasi.

Aktivitas ini dapat dilakukan dengan menggunakan web browser. Interface yang bisa dipergunakan dalam menjembatani terjadinya kolaborasi informasi selain web 
browser, yaitu mailing list, forum diskusi, bahkan jika diperlukan aplikasi customer service. Adapun komponen yang ada dalam sistem untuk mensuplai berbagai kegiatan tersebut meliputi: database, web platform, data management tools, perangkat pengirim pesan, search engine, web service, document management serta interference engine. Teknologi yang dibutuhkan untuk menunjang layanan tersebut diantaranya adalah aplikasi client-server, web service serta artificial intelligence (AI).

Dalam penerapan model knowledge management di FKIP Unpatti Ambon juga harus didukung oleh sumber daya manusia yang berkualitas. Sumber daya manusia tersebut memiliki informasi, pengalaman dan keahlian yang dibutuhkan. Selain itu, teknologi informasi yang tepat guna, serta mempunyai budaya sharing knowledge.

\section{DAFTAR PUSTAKA}

[1] Sensue, Dana I., et al., 2011, Knowledge Management Model and Strategy of Genetic Resources and Traditional Knowledge in Indonesia, Depok: IJCSI International Journal of Computer Science Issues.

[2] Chasanah Nur. et al., 2014., Development Customer Management (CKM) Models in Purbalingga Hospitalilty Using Soft System Methodology (SSM). Juornal of Information System.
[3] Rakhmah, Syifa. 2017., Strategi Knowledge Management Untuk Meningkatkan Pengetahuan Berdasarkan Knowledge Based Organizational Model. Information system For Education And Profesional.

[4] Assegaff, Setiawan., 2017., Evaluasi Pemanfaatan Media Sosial sebagai Sarana Knolwedge Sharing. Jurnal Manajemen Teknologi.

[5] Turban, E. (2008). Information Technology for Management . Transforming Organizations in the Digital Economy (6th Edition ed.). Hoboken: John Wiley \& Sons.

[6] Aarons, J. (2006). Ephistemology and Knowledge Management. In D. G. Schwartz, Encyclopedia of Knowledge Management (p. 166). Hershey: IDEA Group, Inc.

[7] Iivari, J. (2000). Reflections on the role of knowledge management in information economy. In F. Burnstein, \& H.Linger, Knowledge Management for Information Communities. Melbourne..

[8] "Nonaka, I., \& Takeuchi, H. (1995). The Knowledge - Creating Company: How Japanese Companies Create the Dynamics of Innovation. New York: Oxford University Press.

[9] "Hidajat, J., \& Crestofel, D. (2006). Knowledge Management dalam Konteks Organisasi Pembelajar. Bandung : SBM ITB.

[10] Checkland, P., Scholes, J., 1991, Soft System Methodology in Action, Chichester. Wiley..

[11] Probs, Gilberts, Steffen Raub, Kai Romhardt, 2000, Knowledge Management: Building Block for Succes, Chichester, England: John Wiley \& Sons Ltd.

[12] Denvort, T. H., et al., 1998, Succesfull Knowledge Management Project, Sloan Management Review, Winter. 